\title{
PREVALENCE OF BETA-HAEMOLYTIC STREPTOCOCCAL THROAT INFECTIONS IN PAEDIATRIC AGE GROUP IN MADURAI
}

\author{
Sugumari Chandrasegaran ${ }^{1}$, Mahesh Prabhu Subramaniyan ${ }^{2}$
}

${ }_{1}^{1}$ Senior Assistant Professor, Department of Microbiology, Institute of Microbiology, Madurai Medical College, Madurai. ${ }^{2}$ Senior Assistant Professor, Department of Microbiology, Institute of Microbiology, Madurai Medical College, Madurai.

\begin{tabular}{l}
\hline ABSTRACT \\
PURPOSE \\
To assess the prevalence of Streptococcal sore throat infections in the paediatric age group in order to provide prompt treatment \\
at an early stage to reduce the fatal consequences of post-infectious sequelae.
\end{tabular}

\section{MATERIALS AND METHODS}

This study was undertaken from July - December 2015 in 100 children presenting with fever and sore throat. The presumptive identification of Beta haemolytic Streptococci by Bacitracin sensitivity and PYRase test were later confirmed by Latex Agglutination Test. Antibiotic sensitivity was performed by Kirby-Bauer disc diffusion method according to CLSI (Clinical and Laboratory Standards Institute) standards.

\section{RESULTS}

Out of 100 samples collected, Beta haemolytic streptococci were isolated from 76 samples (76\%), in which 64 isolates (64\%) belonged to Lancefield group A Streptococci.

\section{CONCLUSION}

The prevalence of Group A Beta haemolytic streptococci was more in paediatric patients in the age group of 11-13 years (34\%) and less in the age group of 5-7 (14\%). Therefore, a continued surveillance is imperative to monitor the epidemiological trends. An early treatment with appropriate antibiotics will reduce the morbidity and mortality due to complications.

\section{KEYWORDS}

Beta Haemolytic Streptococci, Kirby-Bauer, Surveillance.

HOW TO CITE THIS ARTICLE: Chandrasegaran S, Subramaniyan MP. Prevalence of beta-haemolytic streptococcal throat infections in paediatric age group in Madurai. J. Evolution Med. Dent. Sci. 2016;5(58):3980-3984, DOI: 10.14260/jemds/2016/911

\begin{abstract}
INTRODUCTION
Many visits to primary care providers each year are found to be for sore throat. It has been estimated that approximately 7 sore throat episodes occur per child per year with $13.5 \%$ of these being caused by the Group A Streptococcus.(1) Streptococcus pyogenes is the most common bacterial cause of acute pharyngitis.(2), accounting for $15-30 \%$ of cases in children who usually require treatment with appropriate antibiotics.

Streptococcus pyogenes was first isolated by Rosenbach from human suppurative lesions in the year 1884 . Streptococcus pyogenes is a beta-haemolytic bacterium belonging to Lancefield serogroup A (Group A Streptococci) and has remained as a significant human pathogen for centuries. The diseases caused by Group A Streptococcus range from pyoderma to severe invasive infections. $(3,4)$ and the post streptococcal acute rheumatic fever and acute glomerular nephritis.(5), two potentially serious non-suppurative complications. The other suppurative complications include peritonsillar abscess, mastoiditis, sinusitis, otitis media, bacteraemia and pneumonia.
\end{abstract}

Financial or Other, Competing Interest: None.

Submission 13-06-2016, Peer Review 07-07-2016,

Acceptance 13-07-2016, Published 19-07-2016.

Corresponding Author:

Dr. Sugumari Chandrasegaran,

\#A 54, Santhinikethan Apartments,

Anna Nagar, Madurai-625020.

E-mail: doctorsugumari@yahoo.com,

vedamanjari@gmail.com

DOI: $10.14260 /$ jemds/2016/911
Streptococcal throat infection is spread by direct, close contact with an infected person or through droplets and thus crowding as may be found in schools, increases the rate of transmission of infection.

The streptococcus organism is easy to isolate in the blood agar plate and the treatment of streptococcal infection with antibiotics is simple, which will reduce the morbidity and mortality due to suppurative and non-suppurative complications. Penicillin is the treatment of choice.(6) and it has remained the most effective treatment for a long time. However, it is imperative to look for the emergence of resistance to penicillin in our locality. More importantly, resistance to other antibiotics such as Macrolides is on the increase, which can be monitored only by regular testing of Group A Streptococcus strains to such antibiotics.(7)

Rheumatic Heart Disease (RHD) follows Rheumatic Fever (RF), as a non-suppurative manifestation of Group A Streptococcal pharyngitis. (8) Carditis due to Acute Rheumatic Fever causes the heart valve to be permanently damaged. Valvular damage remains the most common acquired heart disease worldwide. ${ }^{(9)}$ and is the major cause of cardiovascular death in developing countries. Death or total disability may occur years after the initial presentation of carditis.

This study is based on the prevalence of beta-haemolytic Group A Streptococcus isolated from the throats of children presenting with fever and throat pain in a tertiary care centre in Madurai and the antibiotic susceptibility pattern of the organism is studied. 


\section{MATERIALS AND METHODS}

\section{Settings}

This prospective study was conducted in a tertiary care hospital, Madurai Medical College, Madurai.

\section{Study Period}

The study was conducted for 6 months from July-December 2015.

\section{Sample Size}

The study population consisted of 100 children in the age group of 5 to 13 years, who were presenting with sore throat and fever of more than $38.5^{\circ} \mathrm{C}$, in the paediatric OPD in Government Rajaji Hospital, Madurai, after obtaining Institutional Ethical Committee Clearance certificate in the month of June 2015. Informed consent from the parents of children under study at the time of collecting throat swabs.

\section{Inclusion Criteria}

- Paediatric OPD patients in the age group of 5 to 13 years.

- Patients presenting with a history of fever and throat pain.

\section{Exclusion Criteria}

- Patients below 5 years of age and above 13 years of age.

- Patients presenting with complaints other than fever and sore throat.

- Patients who were admitted in the ward, as they were on broad-spectrum antibiotics.

- Outpatients who had taken antibiotics or used antiseptic mouth wash.

\section{Specimen Collection}

After taking proper history and obtaining informed consent from their parents, throat swabs were collected from the children under study. Care was taken not to touch the tongue or buccal surface. The two swabs were collected from the same areas from each patient, one for the purpose of direct smear and the other one for culture. The swabs were placed in sterile test tubes, properly labelled and they were immediately transported to the Microbiological Laboratory.

\section{Processing of the Samples}

Immediately upon receipt in the Microbiological Laboratory, one of the collected throat swabs was used for direct smear preparation by Gram staining. Another throat swab was rubbed over a blood agar plate for culture. The plates were incubated for $24-48$ hours at $37^{\circ} \mathrm{C}$ under an atmosphere containing 5-10 percent $\mathrm{CO}_{2}$. examined for the presence of beta-haemolysis.

The colonies were further processed to confirm the betahaemolytic colonies as Streptococci by subjecting to biochemical reactions like Gram Staining and catalase test. The colonies were submitted to specific identification tests for Group A Streptococcus.

\section{IDENTIFICATION TESTS}

Group A Streptococci were identified from the Isolated Beta-Haemolytic Streptococci Colonies by subjecting to the following Tests
Bacitracin Sensitivity Test (Low Concentration Bacitracin Disc (0.04 Units)

A $\beta$-haemolytic streptococcus showing any zone of inhibition around the bacitracin disc on a blood agar plate was reported as Streptococcus pyogenes.

\section{PYRase Test}

Presumptive identification of a strain as a Group A Streptococcus was also made on the basis of production of the enzyme L-pyrrolidonyl-beta-naphthylamide (PYRase). Among the beta-haemolytic Streptococci isolated from the throat culture, only Group A isolates produce PYRase and hence PYRase test was also conducted in the samples.

\section{Latex Agglutination Test}

The presumptive identification was further confirmed by latex agglutination tests (Strep A Stick One-Step Test by Novamed).

\section{Antibiotic Susceptibility Testing}

Antibiotic susceptibility testing was performed on the blood agar by the Kirby-Bauer disc diffusion method by using discs according to the CLSI (Clinical and Laboratory Standards Institute) standards. The antibiotics which were tested include Penicillin-G (10 $\mu \mathrm{g})$, Erythromycin $(15 \mu \mathrm{g})$, Clindamycin $(2 \mu \mathrm{g})$, Ceftriaxone $(30 \mu \mathrm{g})$, Cotrimoxazole $(25 \mu \mathrm{g})$ and Ofloxacin $(5$ $\mu \mathrm{g})$. From the zone of inhibition, sensitivity pattern for each antibiotic was derived.

\section{OBSERVATIONS AND RESULTS}

A total of 100 samples were collected from the paediatric patients in the age group of 5-13 years who were presenting with fever and throat pain.

\begin{tabular}{|c|c|c|}
\hline Sex & Total No. of Patients & Percentage \\
\hline Male & 50 & 50 \\
\hline Female & 50 & 50 \\
\hline \multicolumn{2}{|c|}{ Table 1: Sex Distribution of Study Population (n=100) } \\
\hline
\end{tabular}

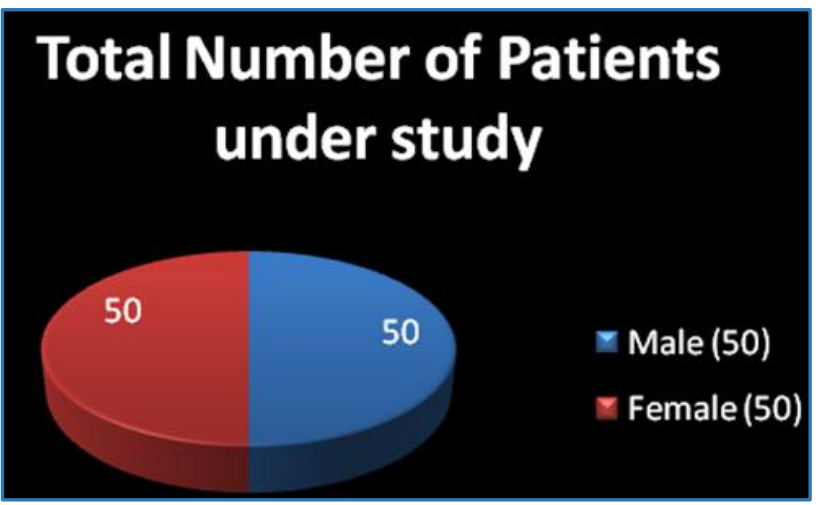

Chart 1: Sex Distribution of Study Population (n=100)

Table 1 (Chart 1 ) shows that out of 100 patients who were under study, 50 were male patients (50\%) and 50 female patients (50\%).

\begin{tabular}{|c|c|c|c|c|c|c|}
\hline Age & \multicolumn{2}{|c|}{ Total Patients } & \multicolumn{2}{c|}{ Male } & \multicolumn{2}{c|}{ Female } \\
\cline { 2 - 7 } Group & No. & Percentage & No. & Percentage & No. & Percentage \\
\hline $05-07$ & 24 & 24 & 16 & 32 & 8 & 16 \\
\hline $08-10$ & 30 & 30 & 12 & 24 & 18 & 36 \\
\hline $11-13$ & 46 & 46 & 22 & 44 & 24 & 48 \\
\hline Total & $\mathbf{1 0 0}$ & $\mathbf{1 0 0}$ & $\mathbf{5 0}$ & $\mathbf{1 0 0}$ & $\mathbf{5 0}$ & $\mathbf{1 0 0}$ \\
\hline \multicolumn{6}{|c|}{ Table 2: Age Distribution of Study Population (n=100) } \\
\hline
\end{tabular}




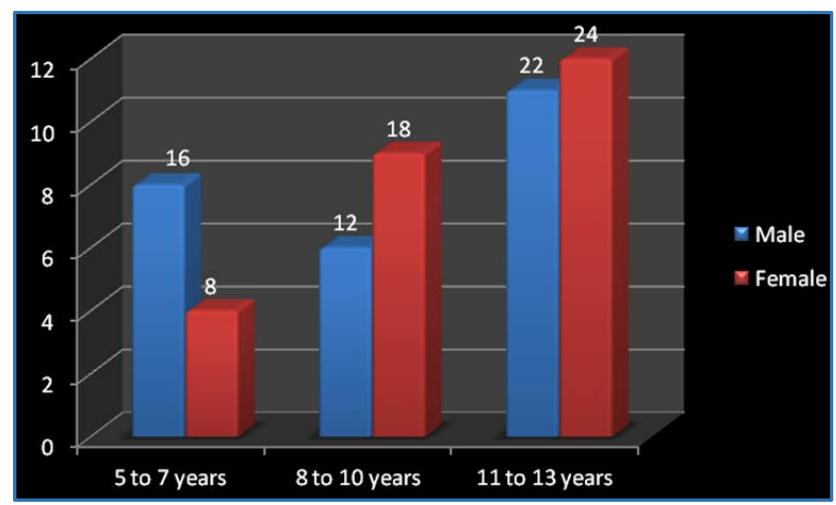

Chart 2: Sex Distribution of Study Population in Different Age Groups ( $n=100)$

Table 2 (Chart 2) shows that out of 100 patients under study, 24 patients ( 16 male, 8 female) were in the age group of 5 to 7 years (24\%), 30 patients ( 12 male, 18 female) were in the age group of 8 to 10 years (30\%) and 46 patients ( 22 male, 24 female) were in the age group of 11 to 13 years (46\%).

The 100 samples collected were processed in the Microbiological Laboratory and $\beta$-haemolytic streptococci were isolated from 76 samples in the blood agar plate.

\begin{tabular}{|c|c|c|}
\hline Group & No. of Isolates & Percentage \\
\hline A & 64 & 84.2 \\
\hline Others & 12 & 15.7 \\
\hline \multicolumn{2}{|c|}{ Table 3: Distribution of $\boldsymbol{\beta}$-Haemolytic } \\
Streptococci $(\boldsymbol{n}=76)$ \\
\hline
\end{tabular}

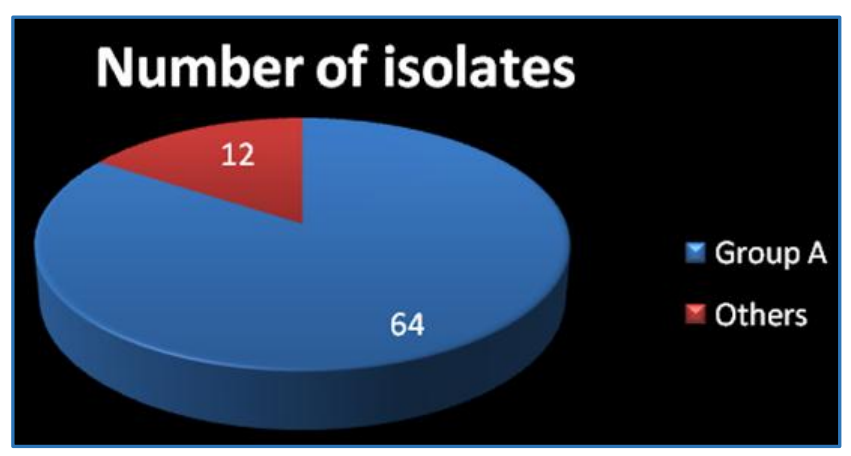

Chart 3: Distribution of $\beta$-Haemolytic Streptococci $(n=76)$

Table 3 (Chart 3) shows that out of $76 \beta$-haemolytic colonies, 64 were found to be belonging to Group A Streptococci by the specific identification tests such as Bacitracin sensitivity test, PYRase test and latex agglutination test.

\begin{tabular}{|c|c|c|c|c|c|c|}
\hline Age & Total Patients & \multicolumn{2}{|c|}{ Male } & \multicolumn{2}{c|}{ Female } \\
\cline { 2 - 7 } Group & No. & Percentage & No. & Percentage & No. & Percentage \\
\hline $5-7$ & 14 & 14 & 10 & 10 & 4 & 4 \\
\hline $8-10$ & 16 & 16 & 6 & 6 & 10 & 10 \\
\hline $11-13$ & 34 & 34 & 14 & 14 & 20 & 20 \\
\hline Total & $\mathbf{6 4}$ & $\mathbf{6 4}$ & $\mathbf{3 0}$ & $\mathbf{3 0}$ & $\mathbf{3 4}$ & $\mathbf{3 4}$ \\
\hline \multicolumn{6}{|c|}{$\begin{array}{c}\text { Table 4: Distribution of Group A } \\
\text { Streptococcus Isolates (n=64) }\end{array}$} \\
\hline
\end{tabular}

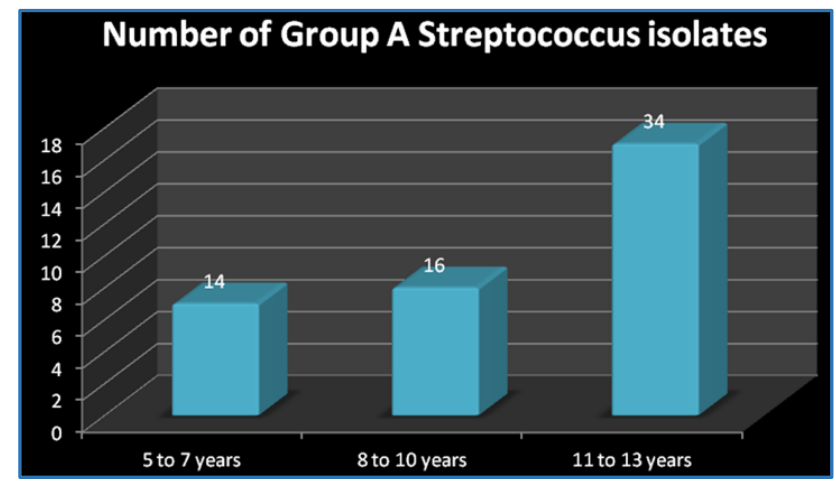

Chart 4: Distribution of Group A Streptococcus Isolates $(n=64)$

Table 4 (Chart 4) shows that among the samples from which Group A Streptococci were isolated (64 samples), 14 samples were collected from the patients in the age group of 5-7 years (14\%), 16 samples in the age group of 8-10 years $(16 \%)$ and 34 samples in the age group of $11-13$ years $(34 \%)$.

\begin{tabular}{|c|c|c|c|c|c|c|}
\hline \multirow{2}{*}{ Antibiotic } & \multicolumn{2}{|c|}{ Sensitive } & \multicolumn{2}{|c|}{$\begin{array}{c}\text { Intermediate } \\
\text { Sensitive }\end{array}$} & \multicolumn{2}{c|}{ Resistant } \\
\cline { 2 - 7 } & $\begin{array}{c}\text { No. of } \\
\text { Isolates }\end{array}$ & $\%$ & $\begin{array}{c}\text { No. of } \\
\text { Isolates }\end{array}$ & $\%$ & $\begin{array}{c}\text { No. of } \\
\text { Isolates }\end{array}$ & $\%$ \\
\hline $\begin{array}{c}\text { Ceftriaxone } \\
(30 \mu \mathrm{g})\end{array}$ & 52 & $81.25 \%$ & 6 & $9.38 \%$ & 6 & $9.38 \%$ \\
\hline $\begin{array}{c}\text { Cotrimoxazole } \\
(25 \mu \mathrm{g})\end{array}$ & 14 & $21.88 \%$ & 8 & $12.50 \%$ & 42 & $65.62 \%$ \\
\hline $\begin{array}{c}\text { Erythromycin } \\
(15 \mu \mathrm{g})\end{array}$ & 32 & $50.00 \%$ & 18 & $28.13 \%$ & 14 & $21.88 \%$ \\
\hline $\begin{array}{c}\text { Penicillin-G } \\
(10 \mu \mathrm{g})\end{array}$ & 34 & $53.13 \%$ & 18 & $28.13 \%$ & 12 & $18.75 \%$ \\
\hline $\begin{array}{c}\text { Oxacillin } \\
(5 \mu \mathrm{g})\end{array}$ & 34 & $53.13 \%$ & 20 & $31.25 \%$ & 10 & $15.63 \%$ \\
\hline $\begin{array}{c}\text { Clindamycin } \\
(2 \mu \mathrm{g})\end{array}$ & 42 & $65.63 \%$ & 6 & $9.38 \%$ & 16 & $25.00 \%$ \\
\hline \multicolumn{7}{|c|}{ Table 5: Antibiotic Sensitivity Pattern (n=64) } \\
\hline
\end{tabular}

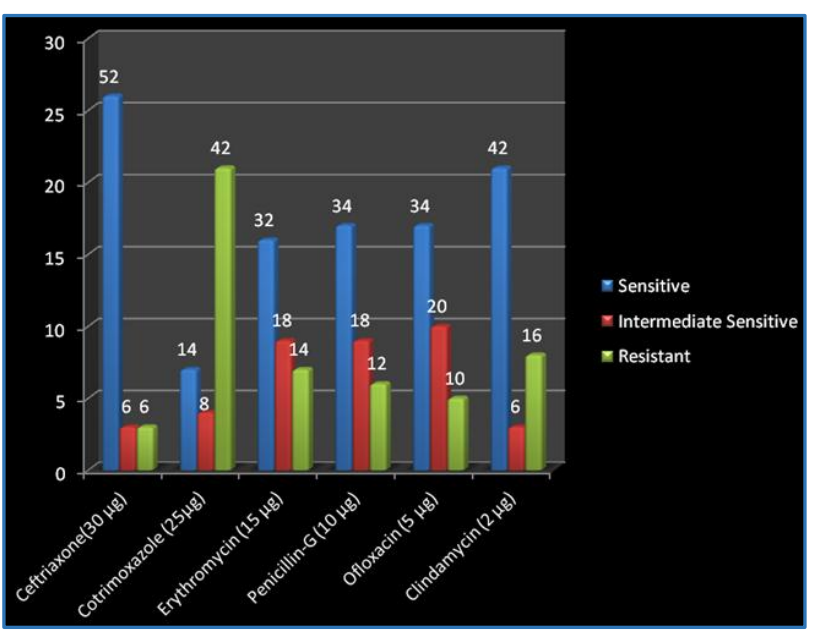

Chart 5: Antibiotic Sensitivity Pattern ( $n=64)$

The results of the Antibiotic Susceptibility Testing done by the Kirby-Bauer disc diffusion method according to the CLSI standards. Table 5 (Chart 5) shows that out of the 64 isolates, Ceftriaxone showed high sensitivity $(81.25 \%)$ followed by Clindamycin (66\%). Oxacillin was intermediate sensitive (31.25\%) followed by Penicillin G and Erythromycin (28.13\% each). Cotrimoxazole was highly resistant (65.62\%). Penicillin showed $53.13 \%$ sensitivity. 


\section{DISCUSSION}

In the present study, the incidence of $\beta$-haemolytic streptococcal infection in the paediatric patients in the age group of 5 to 13 years presenting with sore throat and pyrexia in Government Rajaji Hospital, Madurai was $76 \%$. This is comparable with the study undertaken by Lakshmana Gowda Krishnappa et al ${ }^{10}$, in which the incidence of $\beta$-haemolytic infection in the symptomatic school children was found to be 83.6\%. In the same study conducted by Lakshmana Gowda Krishnappa et $\mathrm{al}^{10}$, the carriage rate in asymptomatic school children was found to be lower (11.3\%), which is comparable with the study conducted by Suresh Kumar et al ${ }^{11}$ among normal school children in Patiala area, in which the carriage rate was reported to be $10.2 \%$. Hence, the prevalence of $\beta$ haemolytic streptococcal infection is more in the symptomatic patients than in the asymptomatic carriers.

Out of $76 \beta$-haemolytic streptococci isolates obtained from 100 samples, 64 isolates were found to be belonging to Group A (84.2\% of $\beta$-haemolytic streptococci isolates). This is in concordance with the study conducted by Suresh Kumar et al ${ }^{11}$ in Patiala area, in which the most common antigenic group was reported to be $\mathrm{A}(86.25 \%)$. S. Kalpana et $\mathrm{al}^{12}$ also reported that the prevalence of Group A Streptococcus was high comparing to other groups of streptococcus.

The prevalence of Group A Streptococci in the paediatric patients presenting with fever and throat pain in Govt. Rajaji Hospital, Madurai, was 64\% (64 isolates from 100 samples) and it is in discordance with the study conducted by $\mathrm{C}$. Sindhulina et al ${ }^{13}$ in a South Indian Hospital among the children with complaints of sore throat, which reported with very low rates of $6 \%$ prevalence. This may be due to the heterogeneity of the organism in the present study; the prevalence of Group A Streptococcal infection was more in females (34\%) and less in males (30\%), but this prevalence rate is less significant.

In the present study, the prevalence of Group A Streptococcal infection was more in the paediatric patients in the age group of 11-13 years (34\%) and less in the age group of 5-7 years $(14 \%)$. This is in concordance with the metaanalysis conducted by Nader Shaikh et al ${ }^{14}$, which states that the paediatric children in younger age group had a lower prevalence of Group A Streptococcal infection.

The antibiotic sensitivity pattern showed $53.13 \%$ sensitivity to Penicillin-G, which is comparable with the study conducted by Abdulwahab et al 15 , in which $48 \%$ sensitivity has been reported. In the present study, the antibiotic sensitivity pattern also showed $81.25 \%$ sensitivity to Ceftriaxone, $21.88 \%$ sensitivity to Cotrimoxazole, $65.63 \%$ sensitivity to Clindamycin, $53.13 \%$ sensitivity to Ofloxacin and $50 \%$ sensitivity to Erythromycin.

In this study, 12 isolates (18.75\%) showed resistance to Penicillin-G, while $100 \%$ sensitivity to Penicillin has been reported by Suresh Kumar et al ${ }^{11}$ in their study. In this study, 14 isolates (21.88\%) showed resistance to Erythromycin, which correlated with the study conducted by Dheepa Muthusamy et al ${ }^{16}$, which reported $23.07 \%$ resistance to Erythromycin.

In this study 42 isolates (70\%) showed resistance to Cotrimoxazole. Uzma Malik et $\mathrm{al}^{17}$ noted that, some of the Streptococcus pyogenes strains showed resistance against Cotrimoxazole (88\%). This study correlates with our study.

\section{CONCLUSION}

The incidence of Group A beta-haemolytic streptococci among the symptomatic paediatric patients presenting with sore throat and fever in Madurai is higher (64\%). Hence, routine throat swabs are to be collected from children with acute tonsillitis and pharyngitis and proper treatment is to be provided taking into account the antibiotic sensitivity of the organism and thus to reduce the post infectious sequelae.

In suspected or culture proven cases of streptococcal throat infection, it is better to prescribe Ceftriaxone in combination with Clindamycin or Ofloxacin, which is cheaper and less toxic in optimal dose and the patient should be advised to take full course of treatment. The appropriate treatment should be provided to Group A Streptococcus positive patients to prevent further complications, as Group A Streptococcus affects the Indian population causing high cardiovascular mortality and morbidity every year leading to considerable socio-economic losses.

\section{REFERENCES}

1. Nandi S, Kumar R, Ray P, et al. Group a streptococcal sore throat in a periurban population of northern India; a one year prospective study. Bull World Health Organ 2001;79(6):528-33.

2. Jain A, Shukla VK, Tiwari V, et al. Antibiotic resistance pattern of group-a beta-haemolytic streptococci isolated from north Indian children. Indian J Med Sci 2008;62(10):392-6.

3. Carapetis JR, Steer AC, Mulholand EK, et al. The global burden of group a streptococcal diseases. Lancet Infect Dis 2005;5(11):685-94.

4. Steer AC, Danchin MH, Carapetis JR. Group a streptococcal infections in children. J Paediatric Child Health 2007;43(4):203-13.

5. Carapetis JR, Epidemiology BJ, Kaplan EL. Epidemiology and prevention of group a streptococcal infections: acute respiratory tract infections, skin infections, and their sequelae at the close of twentieth century. Clinical Infectious Diseases 1999;28(2):205-10.

6. Gerber MA, Robert CS, Eaton CB, et al. Prevention of rheumatic fever and diagnosis and treatment of acute streptococcal pharyngitis. AHA Scientific Statements 2009;119:1541-51.

7. doi:10.1161/ Circulationaha.109.191959.

8. Brahmadathan KN, Gladstone P. Microbiological diagnosis of streptococcal pharyngitis: lacunae and their implications. Indian Journal of Medical Microbiology 2006;24(2):92-6.

9. Kumar RK, Tandon R. Rheumatic fever \& rheumatic heart disease: the last 50 years. Indian J Med Res 2013;137(4):643-58.

10. Nordet P. WHO/ISFC global programme for the prevention and control of RF/RHD. J Int Soc Fed Cardiol 1993;3:4-5.

11. Krishnappa LG, Marie MAM, John J, et al. A communitybased study of the rate of beta-haemolytic group a streptococcal infections in symptomatic and asymptomatic school children. Journal of Laboratory Physicians 2014;6(1)64-5.

12. Kumar S, Kanta S. Beta-haemolytic streptococci throat carriage in normal school children in Patiala area. Indian Journal of Medical Microbiology 1992;10(4):227-30. 
13. Kalpana S, Sundar JS, Parameshwari S, et al. Isolation and identification of group a streptococcal infection among slum children in the age group of 5-15 years in Chennaione year prospective study. IOSR Journal of Pharmacy and Biological Sciences 2012;2(1):27-30.

14. Sindhulina $C$, Geethalakshmi $S$, Thenmozhivalli PR, et al. Bacteriological and molecular studies of group a streptococcal pharyngitis in a south Indian hospital. Indian Journal of Medical Microbiology 2007;26(2)197-8.

15. Shaikh N, Leonard E, Martin JM. Prevalence of streptococcal pharyngitis and streptococcal carriage in children: a meta-analysis. Journal of the American Academy of Pediatrics 2010;126(3).
16. Telmesani AMA, Ghazi HO. A study of group a streptococcal bacteria isolation from children less than 12 years with acute tonsillitis, pharyngitis and health primary school children. Journal of Family \& Community Medicine 2002;9(2)23-6.

17. Muthusamy D, Boppe A, Suresh SP. The prevalence of group a beta haemolytic streptococcal carriers among school children in Coimbatore, south India. Journal of Clinical and Diagnostic Research 2012;6(7):1181-3.

18. Malik U, Noor-us-Saba, Qazilbash AA. Antibiogram sensitivity pattern of streptococcus pyogenes and streptococcal pneumoniae from patients from sore throat and pneumonia infections. Pakistan Journal of Biological Sciences 2005;8(8):1146-51. 